\title{
Benign peroxismal positional vertigo: our experience in 40 cases
}

\author{
Subramanya BT ${ }^{1}$, Lohith S. ${ }^{2}$, Sphoorthi $\mathbf{B}^{3}$, Chandralekha T.V.R. ${ }^{4}$ \\ ${ }^{1}$ Dr. Subramanya BT, ${ }^{2}$ Dr. Lohith S., ${ }^{3}$ Dr. Sphoorthi B., ${ }^{4}$ Dr. Chandralekha TVR, all authors are affiliated with \\ Department of ENT, Subbaiah Institute of Medical Sciences, Shimoga, Karnataka, India.
}

Corresponding Author: Dr. Lohith S., Department of ENT, Subbaiah Institute of Medical Sciences, Shimoga, India. E-mail: dr.shivappalohith@gmail.com

\begin{abstract}
Introduction: BPPV is the most common cause of vertigo provoked by certain head position changes. Despite being the most common cause of peripheral vertigo, BPPV is still often misdiagnosed hence it is important to understand BPPV not only because it may avert expensive and often unnecessary investigations, but also because treatment by particle reposition maneuvers is rapid, easy and effective in more than $90 \%$ of cases. Objectives: 1) To analyze the etiological, clinical and prognostic differences between patients affected by BPPV. 2) To evaluate the efficacy of different PRM in the treatment of BPPV and to compare the results of present study with similar studies done elsewhere. Methods: The present descriptive study was conducted at Department of ENT, Subbaiah institute of medical sciences, Shimoga from August 2015 to August 2018 in 40 patients with a clinical diagnosis of BPPV. All these patients were treated by different PRM specific for the canal involved and the results were analyzed. Results: Right labyrinth was involved in 23 cases $(57.5 \%)$ and left in $17(42.5 \%)$ cases. PC was involved in 34 (85\%) cases and Eply's maneuver was successful in all 34 $(100 \%)$ patients. HC was involved in $6(15 \%)$ cases which were treated with Barbecue and Gufoni maneuver with resolution in 5 (83.33\%) patients. Conclusion: Therapeutic maneuvers are effective in treatment of BPPV that have shown high success rate hence should be tried in all patients with BPPV unless contraindicated to reduce unnecessary diagnostic tests and costs.
\end{abstract}

Keywords: BPPV, Dix Halpike's test, Supine roll test, Epley's maneuver, Barbecue maneuver, Gufoni’s maneuver

\section{Introduction}

Benign paroxysmal positional vertigo (BPPV) is the most common disorder of the peripheral vestibular systemfirst described by Barany in 1921 [1]. The overall prevalence of BPPV is 10.7 to 140 per 100,000 populations [2]. It is a disorder of inner ear where otoliths from the utricular macula detach and move within the lumen of one of the semicircular canals (canalithiasis) and cause endolymph movement or adhere to the cupulae (cupulolithiasis) that stimulates the ampulla of the affected canal, thereby causing repeated episodes of vertigo.

It is precipitated by certain head position changes as may occur with looking up, turning over in bed or straightening up after bending over.It commonly affects older individuals between the fifth and seventh decades of life and has slightly higher incidence in females compared to males. It has been observed that BPPV

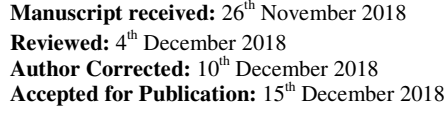

predominantly affects the right labyrinth [3]. In most cases the cause of BPPV idiopathic which accounts for about $50 \%-70 \%$ of cases. The most common cause of "secondary" BPPV is head trauma, representing 7\%$17 \%$ of all BPPV cases which can involve both the ears. Vestibular neuronitis, Meniere's disease, migraine and inner ear surgery have also been shown to be strongly associated with BPPV [4].

BPPV may affect the posterior (PC-BPPV), horizontal (HC-BPPV), or anterior semi-circular canal (AC-BPPV) and in some cases it may even involve more than one canal at a time. The most commonly affected canal is the posterior canal due to its gravity-dependent position, accounting for $85 \%-95 \%$ of cases of BPPV, and the lateral/horizontal canals are affected in approximately $5 \%-15 \%$ of cases. The anterior semicircular canals are rarely affected, accounting for $1 \%-3 \%$ of cases [5]. The most effective treatment for BPPV is Particle reposition maneuver (PRM). Epley's and Semontz maneuver are described for PC-BPPV, Barbecue maneuver 


\section{Original Research Article}

(Lempert's maneuver) and Gufoni's maneuver for HCBPPV and Reverse Epley's for AC-BPPV. Recent studies have shown that the majority of patients are adequately treated with 1 or 2 Particle reposition maneuver [3]. Despite being the most common cause of peripheral vertigo, BPPV is still often under diagnosed or misdiagnosed [5]. It is important to understand BPPV not only because it may avert expensive and often unnecessary investigations, but also because treatment is rapid, easy and effective in more than $90 \%$ of cases [6].

\section{Materials and Methods}

Place and type of study: The present descriptive study was conducted at Department of ENT, Subbaiah institute of medical sciences, Shimoga, in 40 patients with a clinical diagnosis of BPPV from August 2015 to August 2018.

\section{Type of study: Descriptive study}

Inclusion criteria: Patients aged 18 years or older with a clinical diagnosis of BPPV by history and one of the diagnostic positive positional tests for either of the semi circular canals.

Exclusion criteria: Patients having cervical spondylosis or any other cervical spine disorders in whom the reposition maneuvers could not be done and patients who failed to follow up.

In all these patients detailed history was taken and physical examination was carried out including ENT examination, vestibular examination including H.I.N.T.S (Head Impulse, Nystagmus, Test of Skew) and CNS examination including tests for cerebellar function.

Dix- Halpike's test was done, which is considered to be the gold standard test for posterior semicircular canal BPPV. Patient was seatedin uprightposition with the examiner standing at the head end of the patient.The patient's head was rotated $45^{\circ}$ to theright to align the posterior semicircular canal withthe mid-sagittal plane of the body. The patient wasinstructed to keep the eyes open.The patient was moved quickly from the seated to thesupine right-ear-down position and the neck was extended, approximately $20^{\circ}$ below the horizontal plane so that the head hanging off the edge of the table with the support of examiner. The patient's eyes were examined for the latency, duration, and direction of the nystagmus. The patient was asked about thepresence of subjective vertigo. After the resolution of the subjective vertigo andthe nystagmus, if present, the patient was slowlyreturned to the upright position. During the return tothe upright position, a reversal of the nystagmus was be observed.

Test was considered positive if an up beating, torsional (counter clock wise) nystagmus was observed with subjective sensation of vertigo experienced by the patient. If the initial result for the right side was negative, then Dix-Hallpike test wasrepeated for the left side, with the left ear arrivingat the dependent position. If a down beating nystagmus was observed during Dix-Hallpike test, it was considered superior semi circular canal BPPV. If the patient has a history compatible with BPPV andthe Dix-Hallpike test is negative, a supine roll test was performed.

Initially patient was positioned the supine with 30 degree flexion to bring the HC in vertical alignment and the head in neutral position followed by quickly rotating the head 90degrees to one side and the eyes were observed for nystagmus. After the nystagmus subsidesor if no nystagmus is elicited, the head is then returned to the straight faceup supine position. After any additionalelicited nystagmus has subsided, the head is then quicklyturned 90 degrees to the opposite side, and the eyes are onceagain observed for nystagmus. A horizontal geotropic nystagmus was considered positive with intensity of nystagmus stronger on affected side. In cases where apogeotropic nystagmus was observed the side with nystagmus of lesser intensity was considered the affected ear. Summary of interpretation of diagnostic tests and the particle reposition maneuvers used are shown in table 1 . Bow and lean tests were used to detect the affected ear in difficult cases. Frenzel goggle was used to aid the better appreciation of nystagmus during the test. 
Table-1: Summary of interpretation of diagnostic tests and the particle reposition maneuvers performed in present study.

\begin{tabular}{|c|c|c|c|c|c|}
\hline & Side & $\begin{array}{c}\text { PC canalithiasis } \\
\text { or cupulolithiasis }\end{array}$ & $\begin{array}{c}\text { SC canalithiasis or } \\
\text { cupulolithiasis }\end{array}$ & HC canalithiasis & $\begin{array}{c}\text { HC } \\
\text { cupulolithiasis }\end{array}$ \\
\hline Test & & Dix-Halpike's test & Dix-Halpike's test & Supine roll test & Supine roll test \\
\hline Duration & & Paroxysmal & Paroxysmal & Paroxysmal & Persistant \\
\hline $\begin{array}{c}\text { Direction of } \\
\text { nystagmus }\end{array}$ & Right & $\begin{array}{c}\text { Vertical upward } \\
\text { rotational counter- } \\
\text { clock wise }\end{array}$ & $\begin{array}{c}\text { Vertical downward } \\
\text { rotational } \\
\text { counter-clock wise }\end{array}$ & $\begin{array}{c}\text { Horizontal } \\
\text { geotropic toward } \\
\text { right }\end{array}$ & $\begin{array}{c}\text { Horizontal } \\
\text { apogeotropic } \\
\text { toward left }\end{array}$ \\
\cline { 2 - 6 } & Left & $\begin{array}{c}\text { Vertical upward } \\
\text { rotational clock } \\
\text { wise }\end{array}$ & $\begin{array}{c}\text { Vertical downward } \\
\text { rotational clock } \\
\text { wise }\end{array}$ & $\begin{array}{c}\text { Horizontal } \\
\text { geotropic toward } \\
\text { left }\end{array}$ & $\begin{array}{c}\text { Horizontal } \\
\text { apogeotropic to- } \\
\text { ward right }\end{array}$ \\
\hline $\begin{array}{c}\text { Nystagmus } \\
\text { latency }\end{array}$ & Yes & Yes & Yes & No \\
\hline $\begin{array}{c}\text { Particle reposition } \\
\text { maneuver } \\
\text { performed }\end{array}$ & & Eply'smaneuver & Eply's maneuver & $\begin{array}{c}\text { Barbecue } \\
\text { maneuver/ } \\
\text { Gufoni's maneuver }\end{array}$ & $\begin{array}{c}\text { Barbecue } \\
\text { maneuver/ } \\
\text { Gufoni's maneuver }\end{array}$ \\
\hline
\end{tabular}

Epley's maneuver was done in patients with positive Dix-Halpike's test. The patient was initially placed in the upright position with the head turned $45^{\circ}$ toward the affected ear and then rapidly laid back to the supine head-hanging $20^{\circ}$ position, which was maintained for 20-30 seconds. The head was then turned $90^{\circ}$ toward the unaffected side and held for about 20 seconds. The head was again turned a further $90^{\circ}$ such that the patient' head is nearly in the facedown position. This is also held for 20-30 seconds. The patient is then brought into the upright sitting position, completing the maneuver. The Dix-Halpike's test was repeated after Epley's maneuver if negative, treatment ceases. If the repeat test was positive, the maneuver was repeated after few minutes.

Barbecue maneuver was done in patients with positive supine roll test. The patient wasasked to rotate 360 degrees in four stages, a minute apart with the examiner seated at the head end of the examination couch. At the head down position the patient was instructed to rest on theelbows with the neck flexed, so that the horizontal canal isvertical. The supine roll test was repeated and, if negative, treatment ceases. If the repeat test was found positive even after repeating the maneuver 2 to 3 times, Gufoni's maneuver was performed after few minutes.

To perform Gufoni's maneuver the patient was taken from the sitting position to the straightside-lying position on the unaffected side (in canalolithiasis cases) or affected side (incupulolithiasis cases) for about 30 seconds. Then patient's head was quickly turned toward the ground $45^{\circ}-60^{\circ}$ and held in position for 1-2 minutes. The patient then seated up again with the head held towardsthe left shoulder until fully upright. All these patients received Cinnarizine $25 \mathrm{mg}$ SOS for 1day and patients were instructed to sleep in the lateral position with affected ear up overnight.

\section{Results}

A total of 40 cases included in the study. The age of the patients ranged from 19 to 68 years, with mean age of 48 years with standard deviation of 13 and maximum number of patients was in the age group of 51 to 60 years as shown in table 2. Among all patients 18 were male and 22 were female patients with male female ratio of 1:1.2 (table 3)

Table-2: Age distribution of study population.

\begin{tabular}{|c|c|c|}
\hline Age group (years) & No. of patients & \% \\
\hline $11-20$ & 1 & 2.5 \\
\hline $21-30$ & 3 & 7.5 \\
\hline $31-40$ & 9 & 22.5 \\
\hline $41-50$ & 9 & 22.5 \\
\hline $51-60$ & 10 & 25 \\
\hline $61-70$ & 8 & 20 \\
\hline
\end{tabular}


Table-3: Gender distribution of study population.

\begin{tabular}{|c|c|c|}
\hline Gender & No. of patients & \% \\
\hline Male & 18 & 45 \\
\hline Female & 22 & 55 \\
\hline
\end{tabular}

Right labyrinth was involved in 23 cases (57.5\%) and left in 17(42.5\%) cases. Posterior canal was involved in 34 (85\%) cases and horizontal canal was involved in $6(15 \%)$ cases (Table 4). Among PC- BPPV all patients had canalolithiasis where as among HC- BPPV 4 patients had canalolithiasis and 2 patients had cupulolithiasis.

Table-4: Semi circular canal involved in study population.

\begin{tabular}{|c|c|c|}
\hline Semi circular canal involved & No. of patients & \% \\
\hline Posterior & 34 & 85 \\
\hline Horizontal & 6 & 15 \\
\hline Superior & 0 & 0 \\
\hline
\end{tabular}

The duration of symptoms ranged from few hours to 6 months and in majority of patients the presenting symptom was spinning sensation on lying down to the affected side. The aetiologically important factors in our study were idiopathic in $34(84 \%)$ patients, traumatic in $2(5 \%)$, mastoidectomy in $1(2.5 \%)$ and ipsilateral Menier's disease in $1(2.5 \%)$ patient.

Eply's maneuver was successful in all our 34 patients of PC-BPPV with 100\% success rate, among them 33 (97\%) patients had immediate relief of symptoms at first attempt and only 1 patient needed a repeat maneuver. Among 4 patients of canalolithiasis type HC- BPPV, 3 patients had successful treatment with Barbecue maneuver and 1 patient did not respond to both Barbecue as well as Gufoni's maneuver and was treated with forced lateral positionwith affected ear up for $12 \mathrm{hrs}$ in a day for 3 days and pharmacotherapy. Among 2 patients of cupulolithiasis type HC- BPPV one had successful treatment with Barbecue maneuver and other improved with Gufoni maneuver after 3 unsuccessful Barbecue maneuver.

\section{Discussion}

BPPV is considered to be the most common cause of vertigo with overall favorable prognosis. This favorable prognosis is based in part on the fact that BPPV can recover spontaneously. However, undiagnosed and untreated BPPV affects the quality of life especially in elderly individuals increasing the risk for frequent falls and impairment in the performance of daily activities. A large number of patients with BPPV will undergo unnecessary diagnostic testing such as Magnetic resonance imaging, computed tomography scan, ECG, echocardiography and carotid doppler tests as well as pharmacological treatments prior to referral to a specialist [5].

Therefore, significant improvements in the diagnosis and treatment of patients with BPPV may lead to significant health care quality improvements as well as medical and societal cost savings. BPPV is known to affect all age groups, though it appears to be more common in the elderlyin $5^{\text {th }}$ to $7^{\text {th }}$ decade of life and rarely seen in children. In our study, the mean age of the participants was 48 yearswith standard deviation of 13 with maximum number of patients in the age group of 51 to 60 years correlating with that in literature [1,5,7]. In present study the sex distribution indicates a predilection for women which is similar to other studies [1,7].

In majority of cases the cause of BPPV is unknown and the most common identified etiological factors are previous trauma, ipsilateral Meniere's disease, ipsilateralvestibular neuritis and severe systemic disease $[8,9,10,4]$. In our study the cause was unknown in most of patients followed by trauma, mastoidectomy and ipsilateral Menier's disease in that order. According to our study right ear is predominantly affected which is consistent with studies conducted by Brevern MV et al [3] Marciano E et al [1] and Soto-Varela A et al [8]. However Gaur S et al [1] had left ear predilection in their study. The most commonly affected canal in BPPV is the posterior canal due to its gravity-dependent position. In study by Honrubia $\mathrm{V}$ et al. posterior semicircular canal was affected in the $93 \%$ of cases [12]. In a study conducted by SotoVarela A et at on 614 patients of BPPV posterior semicircularcanal was affected in 543 cases (88.4\%), the horizontal in $39(6.4 \%)$ and the superior canal in $32(5.2 \%)$ [13]. In our study $34(85 \%)$ patients had posterior and $6(15 \%)$ patients had horizontal canal involvement. 


\section{Original Research Article}

Treatment of PC-BPPV by particle reposition maneuver was first described by Epley in 1992. In the study conducted by Epley on 30 patients with BPPV, there was $90 \%$ cure rate seen after the maneuver. (14) Similar study was conducted by Parnes et al. in 1993 on 38 patients with BPPV based on positive Dix Hallpike test and symptoms of BPPV and observed a cure rate of $68.5 \%$ [15]. Hardman et al. found a cure rate of 57\%, in a group of 30 patients who were treated by Epley's maneuver. In the present study the success rate of Eply's maneuver was $97 \%$ at first attempt and only 1patient needed repeat maneuver.

The results of PRM in our study is better in PC- BPPV than in the other two canals which is similar to those reported in the literature $[16,17]$. The efficacy of the PRM for posterior canal BPPV in various studies is shown in table 5. There are chances of recurrence of BPPV after complete resolution and hence it is recommended that the patient should be told about a likelihood of recurrences and the patient should be reassessed 1 month after the treatment $[8,18]$.

Table-5: Efficacy of the PRM for posterior canal BPPV in various studies.

\begin{tabular}{|c|c|c|c|}
\hline Reference & No. of patients & Success rate (\%) & No. of treatment sessions \\
\hline Epley [14] & 30 & 100 & Repeated using mastoid vibrator \\
\hline Li [19] & 10 & 100 & Repeated \\
\hline Parnes LS et al [4] & 34 & 88 & Multiple \\
\hline Blackley [20] & 16 & 94 & Single \\
\hline Wolf et al [21] & 102 & 93 & Single \\
\hline Herdman et al [22] & 30 & 90 & Single \\
\hline Present study & 40 & 100 & Single \\
\hline
\end{tabular}

\section{Conclusion}

BPPV affects the quality of life mainly in older individuals the fifth decade of life and has slightly higher incidence in females and morecommonly affects the right labyrinth. PC-BPPV is the most common variety followed by horizontal and anterior canal variants. In majority of cases the cause of BPPV is idiopathic followed by head trauma, vestibular neuronitis, Meniere's disease, migraine and ear surgery. Therapeutic maneuvers are more effective in treating these patients with high success ratehence should be tried in all patients with BPPV unless contraindicated to reduce unnecessary diagnostic procedures and costs.

Abbreviations: BPPV- Benign paroxysmal positional vertigo, PRM- particle reposition maneuver, ACAnterior canal, PC-posterior canal, HC-horizontal canal, SCC-semi circular canal.

\section{Declarations}

Funding: Nil, Conflict of interest: Nil

Permission from IRB: Yes

Ethical approval: Local ethical committee approved

\section{References}

1. Gaur S, Awasthi SK, Bhadouriya SK, et al. Efficacy of Epley's Maneuver in Treating BPPV Patients: A Prospective Observational Study. Int J Otolaryngol. 2015; 2015: 487160. doi: 10.1155/2015/487160. Epub 2015 Oct 1.
2. van der Zaag-Loonen HJ, van Leeuwen RB, et al. Prevalence of unrecognized benign paroxysmal positional vertigo in older patients. Eur Arch Otorhinolaryngol. 2015 Jun; 272 (6):1521-4. doi: 10. 1007/ s00 405-014-3409-4. Epub 2014 Dec 9.

3. von Brevern M, Seelig T, Neuhauser H, et al. Benign paroxysmal positional vertigo predominantly affects the right labyrinth. J Neurol Neurosurg Psychiatry. 2004 Oct; 75 (10): 1487-8. DOI: 10. 1136/jnnp. 2003. 031 500 .

4. Parnes LS, Agrawal SK, Atlas J. Diagnosis and management of benign paroxysmal positional vertigo (BPPV). CMAJ. 2003 Sep 30;169(7):681-93.

5. Bhattacharyya N, Baugh RF, Orvidas L, et al. Clinical practice guideline: benign paroxysmal positional vertigo. Otolaryngol Head Neck Surg. 2008 Nov; 139 (5 Suppl 4):S47-81. doi: 10.1016/j.otohns. 2008.08.022.

6. Xiang-Dong G. Benign paroxysmal positional vertigo. J Neurosci Rural Pract. 2011 Jan;2(1):109-10. doi: 10.4103/0976-3147.80091.

7. Tang $\mathrm{H}, \mathrm{Li} \mathrm{W}$. Advances in the diagnosis and treatment of benign paroxysmal positional vertigo. Exp Ther Med. 2017 Sep;14(3):2424-2430. doi: 10.3892/ etm. 2017.4837. Epub 2017 Jul 25. 


\section{Original Research Article}

8. Soto Varela A, Bartual Magro J, Santos Pérez S, et al. Benign paroxysmal vertigo: a comparative prospective study of the efficacy of Brandt and Daroff exercises, Semont and Epley maneuver. Rev Laryngol Otol Rhinol (Bord). 2001;122(3):179-83.

9. Davies RA, Luxon LM. Dizziness following head injury: a neuro-otological study. J Neurol. 1995 Mar; 242 (4):222-30.

10. Gyo K. Benign paroxysmal positional vertigo as a complication of postoperative bedrest. Laryngoscope. 1988 Mar;98(3):332-3. DOI:10.1288/00005537-19880 3000-00019

11. Marciano E, Marcelli V. Postural restrictions in labyrintholithiasis. Eur Arch Otorhinolaryngol. 2002 May; 259 (5):262-5. Epub 2002 Mar 19. DOI:10. 1007/ s00405-001-0445-7

12. Honrubia V, Baloh RW, Harris MR, et al. Paroxysmal positional vertigo syndrome. Am J Otol. 1999 Jul;20(4):465-70.

13. Soto-Varela A, Santos-Perez S, Rossi-Izquierdo M, et al. Are the three canals equally susceptible to benign paroxysmal positional vertigo? Audiol Neurootol. 2013; 18 (5):327-34. doi: 10.1159/000354649. Epub 2013 Sep 28.

14. Epley JM. The canalith repositioning procedure: for treatment of benign paroxysmal positional vertigo. Otolaryngol Head Neck Surg. 1992 Sep;107(3):399404. DOI:10.1177/019459989210700310

15. Parnes LS, Price-Jones RG. Particle repositioning maneuver for benign paroxysmal positional vertigo.
Ann Otol Rhinol Laryngol. 1993 May;102(5):325-31. DOI:10.1177/000348949310200501

16. Lee SH, Kim JS. Benign paroxysmal positional vertigo. J Clin Neurol. 2010 Jun;6(2):51-63. doi: 10. 3988/jcn.2010.6.2.51. Epub 2010 Jun 30.

17. Prokopakis E, Vlastos IM, Tsagournisakis M, et al. Canalith repositioning procedures among 965 patients with benign paroxysmal positional vertigo. Audiol Neurootol. 2013;18(2):83-8. doi: 10.1159/000343579. Epub 2012 Nov 6.

18. Hornibrook J. Benign Paroxysmal Positional Vertigo (BPPV): History, Pathophysiology, Office Treatment and Future Directions. Int J Otolaryngol 2011; 2011:835671.

19. Li JC. Mastoid oscillation: a critical factor for success in canalith repositioning procedure. Otolaryngol Head Neck Surg. 1995 Jun; 112(6):670-5. DOI:10. 1016/S0194-59989570174-5

20. Blakley BW. A randomized, controlled assessment of the canalith repositioning maneuver. Otolaryngol Head Neck Surg. 1994 Apr;110(4):391-6.

21. Wolf JS, Boyev KP, Manokey BJ, et al. Success of the modified Epley maneuver in treating benign paroxysmal positional vertigo. Laryngoscope. 1999 Jun; 109(6):900-3.

22. Herdman SJ, Tusa RJ, Zee DS, et al. Single treatment approaches to benign paroxysmal positional vertigo. Arch Otolaryngol Head Neck Surg. 1993 Apr;119 (4):450-4.

\section{How to cite this article?}

Subramanya BT, Lohith S, Sphoorthi B, Chandralekha T.V.R. Benign peroxismal positional vertigo: our experience in 40 cases. Trop J Ophthalmol Otolaryngol.2018;3(4):97-102.doi: 10.17511/jooo.2018.i04.07 